\title{
Communication
}

\section{Synthesis, Characterization and Copper(2+) Coordination Chemistry of a Polytopic Paramagnetic Ligand}

\author{
Nico M. Bonanno ${ }^{1}$, Alan J. Lough ${ }^{2}$, Prashanth K. Poddutoori ${ }^{1}$ and Martin T. Lemaire ${ }^{1, *}$ \\ 1 Department of Chemistry, Brock University, St. Catharines, ON L2S 3A1, Canada; \\ NB15SZ@brocku.ca (N.M.B.); ppodduto@brocku.ca (P.K.P.) \\ 2 Department of Chemistry, University of Toronto, Toronto, ON M5S 3H6, Canada; alough@chem.utoronto.ca \\ * Correspondence: mlemaire@brocku.ca; Tel.: +1-905-688-5550
}

Academic Editor: Coen de Graaf

Received: 28 October 2016; Accepted: 7 February 2017; Published: 14 March 2017

\begin{abstract}
We describe the synthesis of a new tetratopic phenoxyl radical ligand based on the previously reported ditopic "baqp" radical. The tetratopic ligand is prepared in five steps from 4-tert-butylphenol. Coordination of the ligand with $\mathrm{Cu}(\mathrm{OAc})_{2}$ produced a tetranuclear complex with an $S=\frac{1}{2}$ ground state featuring a coordinated hexa-anion radical with very strong intramolecular antiferromagnetic exchange coupling.
\end{abstract}

Keywords: redox-active ligands; polytopic ligands; copper; magnetic exchange coupling

\section{Introduction}

The coordination chemistry of redox-active ligands (RALs) is currently an active area of synthetic research with a wide scope of potential applications, including catalysis [1-3], bio-mimetics [4,5], and materials [6-8]. Redox-active ligands share an important trait in common with transition metal ions-the ability to exist in multiple charge and spin configurations and as a result RALs are often found to be in paramagnetic oxidation states when coordinated to transition metal ions. This aspect of RAL chemistry has been exploited to produce transition metal complexes with very strong intramolecular magnetic exchange couplings leading to interesting properties, including single molecule magnet behavior [9-11]. Recently we synthesized a ditopic bridging ligand baqp 1 (Figure 1) that when uncoordinated provides an unusual example of a stable phenoxyl radical [12]. Herein we show that the synthetic method used to prepare $\mathbf{1}$ can be extended to produce paramagnetic ligands with greater topicity. The synthesis and characterization of the tetratopic analogue of $\mathbf{1}$ is described. We also present a tetranuclear $\mathrm{Cu}^{2+}$ complex containing the polytopic ligand in a $S=\frac{1}{2}$ state with very strong $\mathrm{Cu}$-radical exchange coupling.<smiles>COc1c(Nc2cccc3cccnc23)cc(C(C)(C)C)cc1Nc1cccc2cccnc12</smiles>

Figure 1. Structure of baqp 1. 


\section{Results and Discussion}

The paramagnetic phenoxyl ligand 4 is prepared in five steps from 4-tert-butylphenol. Iodination, protection of the phenol, and Buchwald-Hartwig cross-coupling [13] with one equivalent of 8 -aminoquinoline afforded mono-iodosubstituted 2. Two equivalents of 2 were reacted with commercially available 2,6-diamino-4-tert-butylanisole to produce the tri-methoxy protected 3 (Scheme 1; Figures S1-S4). Crystals of 3 suitable for X-ray crystallography were obtained from the slow diffusion of water into a THF solution of $\mathbf{3}$. The molecular structure of $\mathbf{3}$ is presented in Figure 2 with crystallographic and metrical properties reported in Tables S1 and S2. In the crystal structure of 3 there are three independent molecules, one of which is shown in Figure 2 (the structures of the other two independent molecules of 3 can be found in Supplementary Materials Figure S5). In the structure of 3, the contiguous inner three phenyl rings are out-of-plane with respect to one another, with the central ring tilted with respect to the plane containing the two adjacent rings (the structural properties of the two other independent molecules are similar). In Figure 2, the dihedral angle between the central and adjacent phenyl rings is $49.9(2)^{\circ}$ and between the central phenyl ring and the quinoline ring is $16.9(2)^{\circ}$.

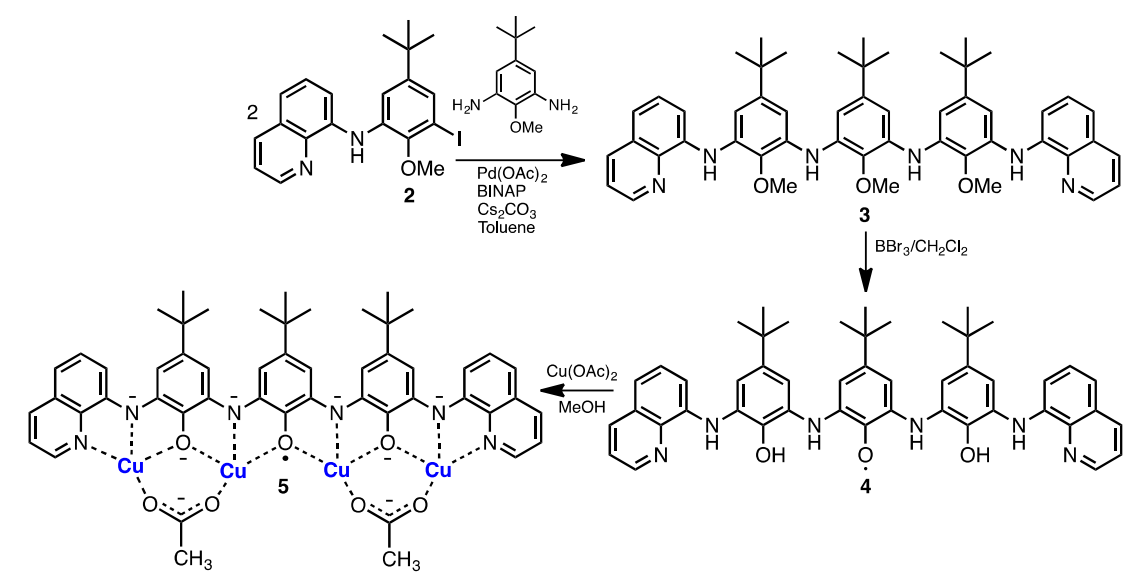

Scheme 1. Synthesis of paramagnetic ligand 4 and complex 5. Spectroscopic data suggests 4 is further oxidized (oxidized 4) possibly to a triphenoxyl radical but other paramagnetic configurations are possible.

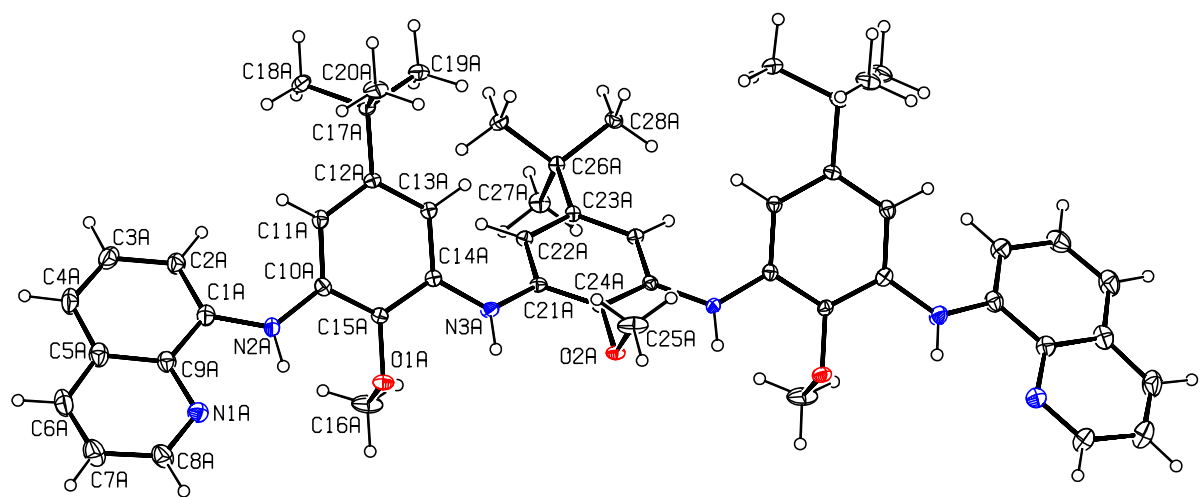

Figure 2. Displacement ellipsoid plot (30\% probability) of one of the three independent molecules of 3. Unlabeled atoms are generated by the symmetry code $(-x+1, y, z)$. Crystal data. $\mathrm{C}_{157} \mathrm{H}_{182} \mathrm{~N}_{18} \mathrm{O}_{10}$, $M=2481.20$, orthorhombic, $a=40.5622(15), b=16.6179(6), c=11.4245(4) \AA, U=7700.8(5) \AA^{3}, T=147(2) \mathrm{K}$, space group $P m c 2_{1}, Z=2,147,458$ reflections measured, 13,873 unique $\left(R_{\text {int }}=0.0814\right)$ which were used in all calculations. The final $w R\left(F^{2}\right)$ was 0.1712 (all data). CCDC deposit 1491850. 
Deprotection of 3 in the presence of $\mathrm{BBr}_{3}$ solution produced a brown paramagnetic compound 4 following work-up under an inert atmosphere that over approximately $48 \mathrm{~h}$ converted to a black paramagnetic material. Based on the spectroscopic data (Figures S6-S8) from the brown material, we conclude that 4 is a transient mono-phenoxyl radical. We were unable to acquire an NMR spectrum from paramagnetic 4; however, Electrospray ionization (ESI) mass spectrometry presents a base peak that is one $m / z$ unit less than the anticipated $m / z$ for the diamagnetic tri-phenol. We also observed an electron paramagnetic resonance (EPR) spectrum and a low energy band in the UV-Visible-NIR spectrum that were each similar to the spectroscopic properties of $\mathbf{1}$ [12]. Over a period of approximately $48 \mathrm{~h}$, brown compound 4 turns black in color (the black material we refer to as oxidized 4). High-resolution mass spectrometry (Figure S8) of this black material produced an exact mass three units less than anticipated for the fully deprotected tri-phenol; consistent with a triphenoxyl radical structure but there are other possibilities. Our attempts to grow X-ray quality crystals of the oxidized form of 4 have been hindered by the poor stability of this species in solution (in the solid-state, the material is very stable). Other spectroscopic data from oxidized 4 was provided by FT-IR spectroscopy; no $\mathrm{OH}$ stretching absorptions could be identified, only broad (H-bonded) $\mathrm{N}-\mathrm{H}$ stretches that are similar in energy to those found in the protected compound $\mathbf{3}$ were observed (Figure S9). UV-Visible spectroscopy also suggests a phenoxyl radical structure for oxidized 4; a NIR $(\sim 970 \mathrm{~nm})$ absorption of moderate intensity is observed (Figure S10), which was also observed in the electronic spectrum of $\mathbf{1}$ [12]. The higher energy observed for this absorption in oxidized 4 relative to $\mathbf{1}$ is in line with the anticipated decreased planarity. The cathodic electrochemical behavior (DPV) of oxidized 4 in $\mathrm{CH}_{2} \mathrm{Cl}_{2}$ (Figure S11) produces a rich manifold of waves.

The EPR spectrum of oxidized 4 was recorded in the solid state and in solution $\left(\mathrm{CH}_{2} \mathrm{Cl}_{2}\right)$ at room temperature and at $100 \mathrm{~K}$ (Figure S12). In the solid state, a sharp featureless absorption centered at $g=1.986$ is observed at 298 and $100 \mathrm{~K}$. In $\mathrm{CH}_{2} \mathrm{Cl}_{2}$ solution, a similar absorption is observed at $298 \mathrm{~K}$ free of any hyperfine structure consistent with the proposed phenoxyl radical structure. Freezing the solution resulted in a dramatic decrease in EPR signal intensity. We have observed similar behaviour in solutions containing crystalline samples of $\mathbf{1}$, which we are currently investigating and preliminary results suggest reversible formation of diamagnetic $\pi$-dimers in solution at low temperature. Solutions of oxidized 4 are unstable and decompose over time; therefore, we carried out coordination reactions on fresh, deprotected solutions of 4 prior to its oxidation to black oxidized 4.

Coordination of freshly prepared 4 to an excess of $\mathrm{Cu}(\mathrm{OAc})_{2}$ in methanol in the presence of triethylamine produced a dark purple microcrystalline precipitate over the course of about 3 weeks. The microcrystalline material is poorly soluble in most organic solvents with the exception of methanol but is very stable in the solid state. We were unable to grow crystals suitable for X-ray diffraction; however, microanalysis, mass spectrometry, and UV-Vis/FT-IR spectroscopy point to the formula $\mathrm{Cu}_{4} \mathrm{~L}(\mathrm{OAc})_{2} 5$. Charge balance requires that in this complex the ligand $(\mathrm{L})$ is bound as a hexa-anion,

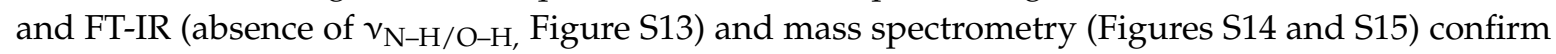
the ligand is fully deprotonated and, therefore, must be paramagnetic with one unpaired electron. The coordinated ligand hexa-anion radical can be considered to be in an iminosemiquinone oxidation state in one interpretation of the electronic structure [14]. Further support for this electronic structure is provided by superconducting quantum interference device (SQUID) magnetometry described later. Two acetates are present to balance the charge and are very likely to be bridging the four coordinated $\mathrm{Cu}^{2+}$ ions (this is supported by FT-IR spectroscopy, where absorptions typical for bridging acetate are noted). The structure that we propose for this complex is provided in Figure 3 and was optimized by density functional theory (DFT). In this structure, four $\mathrm{Cu}^{2+}$ ions are bound by the four binding pockets of the tetratopic ligand (two of the binding pockets feature NNO donor atoms and the inner pockets have $\mathrm{ONO}$ donors). Each of the $\mathrm{Cu}^{2+}$ ions are in a square planar coordination geometry with the fourth coordination site occupied by an $\mathrm{O}$ donor from a bridging acetate. The positive ion mode ESI mass spectrum in $\mathrm{CH}_{3} \mathrm{OH}$ produced an intense base peak at $m / z 1159$, which is consistent with the molecular ion $\left[\mathrm{M}+\mathrm{CH}_{3} \mathrm{OH}+\mathrm{H}^{+}\right]^{+}$including the correct isotope distribution demonstrating the presence of 
four $\mathrm{Cu}$ ions per molecule. The MALDI mass spectrum produced a $\left[\mathrm{M}+\mathrm{Na}^{+}\right]^{+}$peak at $m / z 1150$ as the highest $m / z$ peak in the spectrum. Microanalysis is also consistent with the proposed structure. The UV-Visible spectrum of 5 (Figure S16) exhibits a very intense absorption at $645 \mathrm{~nm}$, which can be typical for transition metal complexes coordinated to iminosemiquinone radical anions $[15,16]$.

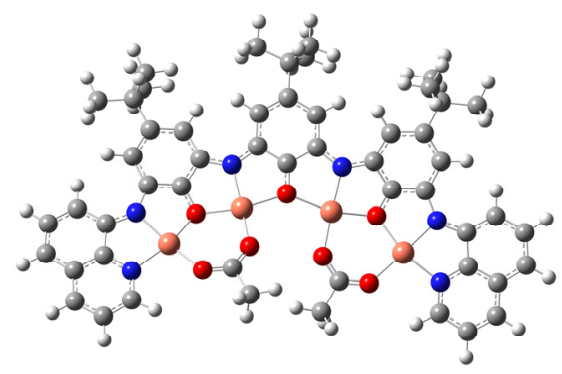

Figure 3. Geometry optimized structure of 5 [BP-86/def2-SVP]. $\mathrm{Cu}=$ gold spheres; $\mathrm{N}=$ blue spheres; $\mathrm{O}=$ red spheres; $\mathrm{C}=$ grey spheres; $\mathrm{H}=$ white spheres.

The variable temperature magnetic properties of 5 were investigated by SQUID magnetometry and the results are plotted in Figure 4. At $320 \mathrm{~K}$ the value of $\chi_{m} T\left(1.03 \mathrm{~cm}^{3} \cdot \mathrm{K} \cdot \mathrm{mol}^{-1}\right)$ is much less than the theoretical value for a spin system containing five uncorrelated $S=\frac{1}{2}$ fragments from four $\mathrm{Cu}^{2+}$ ions and one radical $\left(1.875 \mathrm{~cm}^{3} \cdot \mathrm{K} \cdot \mathrm{mol}^{-1}\right)$. With decreasing temperature there is a steady decrease in $\chi_{m} T$ suggesting antiferromagnetic intramolecular interactions are operative in $\mathbf{5}$. At a very low temperature (5 K) $\chi_{m} T$ is $0.37 \mathrm{~cm}^{3} \cdot \mathrm{K} \cdot \mathrm{mol}^{-1}$, consistent with an $S=\frac{1}{2}$ ground state. The experimental data was fit with a model incorporating four different intramolecular magnetic exchange coupling constants: Two $\mathrm{Cu}$-radical couplings between the two inner $\left(J_{1(\mathrm{Cu}-\mathrm{rad})}\right)$ and two terminal $\left(J_{2(\mathrm{Cu}-\mathrm{rad})}\right) \mathrm{Cu}$ ions with the radical, respectively, and two $\mathrm{Cu}-\mathrm{Cu}$ exchange pathways, one between the terminal $\left(\mathrm{J}_{3(\mathrm{Cu}-\mathrm{Cu} u}\right)$ and inner $\left(\mathrm{J}_{4(\mathrm{Cu}-\mathrm{Cu})}\right) \mathrm{Cu}$ ions and the other between the two inner $\mathrm{Cu}$ ions (Figure 5). The ligand unpaired electron is delocalized over the entire molecule and so all four $\mathrm{Cu}^{2+}$ ions would be exchanged coupled to the ligand. It was anticipated that the two sets of $\mathrm{Cu}$-radical and $\mathrm{Cu}-\mathrm{Cu}$ exchange coupling constants should be antiferromagnetic and of the same order of magnitude, which is what was obtained in the best fit using the simulation program PHI [17] $\left(J_{1(\mathrm{Cu}-\mathrm{rad})}=-517, J_{2(\mathrm{Cu}-\mathrm{rad})}=-260, J_{3(\mathrm{Cu} u-\mathrm{Cu})}=-192\right.$ and $J_{4(\mathrm{C} u-\mathrm{C} u)}=-186 \mathrm{~cm}^{-1} ; z J^{\prime}=-0.93 \mathrm{~cm}^{-1}, g_{a v}=2.05$ (fixed), TIP $=233 \times 10^{-6} \mathrm{~cm}^{3} \cdot \mathrm{mol}^{-1}, \varrho=0.039$ $(S=3 / 2), R=0.0024$. Other models gave similar fits but with either non-plausible exchange coupling constants or other parameters and so they were not used. These alternate models included one that only considered $\mathrm{Cu}$-radical exchange coupling, another with four different $\mathrm{Cu}$-radical exchange coupling constants, or only one $\mathrm{Cu}$-radical exchange coupling. Support for the $S=\frac{1}{2}$ ground state is also provided by EPR spectroscopy. At $100 \mathrm{~K}$ in the solid state an absorption centered at $g=2.059$ is observed with unresolved $\mathrm{Cu}$ hyperfine coupling (Figure S17). Preliminary qualitative broken symmetry (BS) DFT calculations predict a spin density distribution (Figure S18) that is consistent with the proposed electronic structure. The calculated energy of the BS doublet is $355 \mathrm{~cm}^{-1}$ less than the sextet state. 


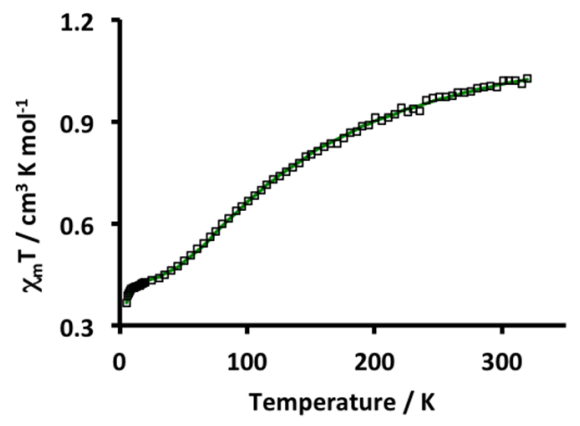

Figure 4. Plot of $\chi_{m} T$ vs. $T$ for 5. Squares represent the experimental data points and the green curve represents the best fit to the experimental data (best fit parameters are provided in the text). External field 5000 Oe.

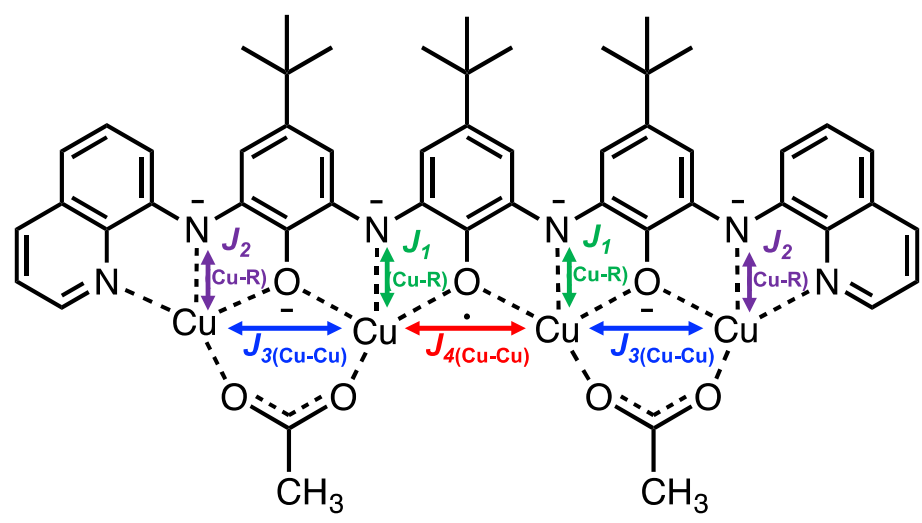

Figure 5. Magnetic exchange pathways in 5. $J_{1}$ and $J_{2}$ represent two distinct $\mathrm{Cu}$-radical exchange pathways involving inner $\left(J_{1}\right)$ and terminal $\left(J_{2}\right) \mathrm{Cu}$ ions. $J_{3}$ and $J_{4}$ represent two different $\mathrm{Cu}-\mathrm{Cu}$ exchange pathways involving the terminal and inner $\mathrm{Cu}$ ions $\left(J_{3}\right)$ and the inner $\mathrm{Cu}$ ions $\left(J_{4}\right)$. The unpaired electron on the ligand is delocalized over the entire molecule and so all four $\mathrm{Cu}^{2+}$ would be expected to engage in an exchange interaction with the radical.

\section{Materials and Methods}

\subsection{General Considerations}

All reagents were commercially available and used as received unless otherwise stated. Anhydrous solvents $\left(\mathrm{CH}_{2} \mathrm{Cl}_{2}\right.$, toluene, diethyl ether) were obtained by distillation over $\mathrm{CaH}_{2}$ or $\mathrm{Na} /$ benzophenone ketyl. ${ }^{1} \mathrm{H} /{ }^{13} \mathrm{C}-\mathrm{NMR}$ spectra at room temperature were recorded on a Bruker Avance III HD 400 Digital NMR spectrometer with a 9.4 $\mathrm{T}$ Ascend magnet using deuterated solvents. FT-IR spectra were recorded on a Shimadzu (IRAffinity spectrometer as $\mathrm{KBr}$ discs. UV-Vis measurements were recorded on a Shimadzu 3600 UV-Vis-NIR spectrophotometer in $\mathrm{CH}_{2} \mathrm{Cl}_{2}$ or methanol solution using quartz cuvettes. Cyclic voltammetry (CV) and differential pulse voltammetry (DPV) experiments were performed with a Bioanalytical Systems Inc. (BASI) Epsilon electrochemical workstation. Oxidized 4 was dissolved in anhydrous solvent $\left(\mathrm{CH}_{2} \mathrm{Cl}_{2}\right)$, and then deaerated by sparging with $\mathrm{N}_{2}$ gas for 10-15 min. Solution concentrations were approximately $10^{-3} \mathrm{M}$ in analyte containing approximately $0.5 \mathrm{M}$ supporting electrolyte $\left(\mathrm{Bu}_{4} \mathrm{NPF}_{6}\right)$. A typical three-electrode set-up was used including a glassy carbon working electrode, $\mathrm{Ag} / \mathrm{AgCl}$ reference electrode, and a platinum wire auxiliary electrode. The scan rate for all $\mathrm{CV}$ experiments was $100 \mathrm{mV} / \mathrm{s}$ (or $25 \mathrm{mV} / \mathrm{s}$ for DPV). Electron impact (EI) and fast atom bombardment (FAB) mass spectra were acquired on a ThermoFisher high resolution double focusing magnetic sector mass spectrometer system. ESI mass spectra were obtained on a Bruker HCT Plus Proteineer LC-MS with electrospray and a syringe pump was used for direct sample infusion. MALDI mass spectra 
were obtained on a Bruker Autoflex TOF/TOF MALDI spectrometer. Variable temperature magnetic susceptibility measurements for $\mathbf{5}$ were recorded on a Quantum Design-Magnetic Property Measuring System (QD-MPMS) SQUID magnetometer at an external magnetic field of 5000 Oe over a temperature range of 5-325 K. The sample was weighed into a gel cap and diamagnetic contributions were calculated using Pascal's constants. EPR measurements on powder samples of oxidized 4 and $\mathbf{5}$ were recorded using a Bruker Elexsys E580 pulse spectrometer operating in continuous wave (CW) mode. Spectra were recorded at 300 and $100 \mathrm{~K}$. Microanalyses were performed by Guelph Chemical Labs (Guelph, ON, Canada).

\subsection{Computational Details}

The geometry optimization and frequency calculation of 5 were carried out using the suite of programs included in the Turbomole 6.5 package [18-20] at the def2-SVP [21,22] level of theory using the BP86 functional [23-25] with the Resolution-of-the-Identity (RI) approximation [26-30] switched on. The calculated geometry was checked to ensure that it was a minimum on the potential energy surface (no negative frequencies). Single point energy calculations were performed on the optimized geometry using the B3LYP $[31,32]$ hybrid functional and the def2-SVP basis set on all atoms with the Gaussian09 (Revision D.01) [33] package. Tight self-consistent field (SCF) convergence criteria were used for all calculations. The program Chemissian [34] was used for the preparation of the spin density distribution figure.

\subsection{Synthesis of $2-5$}

[3-Iodo-2-methoxy-5-(tert-butyl)phenyl]-8-quinolylamine (2). 2,6-diiodo-4-tert-butylanisole ( $3.54 \mathrm{~g}, 8.57 \mathrm{mmol}), \mathrm{Pd}(\mathrm{OAc})_{2}(0.096 \mathrm{~g}, 0.43 \mathrm{mmol}, 5 \mathrm{~mol} \%)$, rac-BINAP $(0.524 \mathrm{~g}, 0.857 \mathrm{mmol}, 10 \mathrm{~mol} \%)$, $\mathrm{Cs}_{2} \mathrm{CO}_{3}(5.59 \mathrm{~g}, 17.1 \mathrm{mmol})$, and 8-aminoquinoline $(1.23 \mathrm{~g}, 8.54 \mathrm{mmol})$ were combined in a Schlenk flask containing dry toluene $(70 \mathrm{~mL})$ under an $\mathrm{N}_{2}$ atmosphere. The mixture was heated to $105^{\circ} \mathrm{C}$ and stirred rapidly at this temperature for $6 \mathrm{~d}$. Reaction progress was monitored by thin layer chromatography (TLC) (25:1 Hex/EtOAc) and small amounts of catalyst/co-catalyst and 8-aminoquinoline were added if consumption of the starting material was not complete. Upon reaction completion the reaction mixture was cooled to room temperature and then diluted with $\mathrm{CH}_{2} \mathrm{Cl}_{2}(250 \mathrm{~mL})$ and $\mathrm{H}_{2} \mathrm{O}(250 \mathrm{~mL})$. The organic layer was separated, pre-absorbed onto silica gel, and evaporated. The solid residue was loaded on top of a large diameter chromatography column and eluted with 25:1 Hex/EtOAc. The product is isolated as the first yellow band to elute from the column. Yield, $2.8 \mathrm{~g}(76 \%) .{ }^{1} \mathrm{H} \mathrm{NMR}$ $\left(400 \mathrm{MHz}, \mathrm{CDCl}_{3}\right): \delta 8.85(\mathrm{~d}, 1 \mathrm{H}, J=3.8 \mathrm{~Hz}), 8.63(\mathrm{br} \mathrm{s}, 1 \mathrm{H}), 8.16(\mathrm{~d}, 1 \mathrm{H}, J=8.3 \mathrm{~Hz}), 7.69(\mathrm{~s}, 1 \mathrm{H})$, 7.49-7.42 (m, 4H), 7.33-7.26 (m, 1H), $3.85(\mathrm{~s}, 3 \mathrm{H}), 1.36(\mathrm{~s}, 9 \mathrm{H}) .{ }^{13} \mathrm{C}$ NMR $\left(100 \mathrm{MHz}, \mathrm{CDCl}_{3}\right): \delta$ 149.4, 148.6, 147.8, 139.6, 139.0, 136.1, 135.0, 128.9, 128.7, 127.2, 121.7, 117.1, 116.9, 108.3, 91.8, 60.3, 34.6, 31.4. FT-IR (KBr): 3360 (w), 3259 (w), 3043 (w), 2960 (m), 1668 (m), 1591 (m), 1573 (m), 1527 (s), 1471 (s), 1431 (m), $1379(\mathrm{~m}), 1365(\mathrm{~m}), 1332(\mathrm{~m}), 1271(\mathrm{~m}), 1201(\mathrm{~m}), 1132(\mathrm{w}), 1114(\mathrm{w}), 1064(\mathrm{w}), 844(\mathrm{w}), 819(\mathrm{~m}), 788$ (m), $746(\mathrm{~m}), 671(\mathrm{w}), 607(\mathrm{w}), 574 \mathrm{~cm}^{-1}(\mathrm{w})$. UV-Vis $\left(\mathrm{CH}_{2} \mathrm{Cl}_{2}\right): \lambda_{\max }=373 \mathrm{~nm}$. HR-MS (EI): Calc'd for $\mathrm{C}_{20} \mathrm{H}_{21} \mathrm{~N}_{2} \mathrm{OI}=432.0693$, found 432.0674 .

2-Methoxy-1,3-bis[2-methoxy-3-(8-quinolylamino)-5-(tert-butyl)phenylamino]-5-(tert-butyl) benzene (3). $2(1.4 \mathrm{~g}, 3.4 \mathrm{mmol}), \mathrm{Pd}(\mathrm{OAc})_{2}(37.6 \mathrm{mg}, 0.168 \mathrm{mmol}, 5 \mathrm{~mol} \%)$, and rac-BINAP $(0.209 \mathrm{~g}$, $0.336 \mathrm{mmol}, 10 \mathrm{~mol} \%)$ were combined in a Schlenk flask containing toluene $(110 \mathrm{~mL})$ under an $\mathrm{N}_{2}$ atmosphere. The solution was stirred for $5 \mathrm{~min}$ at room temperature followed by the addition of 4-tert-butyl-2,6-diaminoanisole $(0.261 \mathrm{~g}, 1.34 \mathrm{mmol})$ and $\mathrm{Cs}_{2} \mathrm{CO}_{3}(1.75 \mathrm{~g}, 5.37 \mathrm{mmol})$. The reaction mixture was refluxed for $7 \mathrm{~d}$. Once completion of the reaction was noted by TLC, the reaction mixture was cooled to room temperature and then diluted with $\mathrm{CH}_{2} \mathrm{Cl}_{2}(250 \mathrm{~mL})$ and $\mathrm{H}_{2} \mathrm{O}(250 \mathrm{~mL})$. The organic layer was separated and pre-absorbed on to silica gel. Purification of 3 via column chromatography was achieved with a gradient elution, starting at 25:1 Hex/EtoAc and changing to 10:1 Hex/EtoAc to collect a yellow band, which was evaporated to a fluffy yellow product. Crystals can be grown by slow diffusion of water into a THF solution of 3 in a narrow diameter tube. Yield, 
$3.36 \mathrm{~g}(78 \%) .{ }^{1} \mathrm{H}$ NMR $\left(400 \mathrm{MHz}, \mathrm{CDCl}_{3}\right): \delta 8.87(\mathrm{~s}, 2 \mathrm{H}), 8.60(\mathrm{~d}, 2 \mathrm{H}, J=5.6 \mathrm{~Hz}), 8.16(\mathrm{~d}, 2 \mathrm{H}, J=8.2 \mathrm{~Hz})$, 7.60-7.43 (m, 6H), 7.37-7.25 (m, 6H), 7.22 (d, 2H, J = 6.9 Hz), $6.67(\mathrm{~d}, 2 \mathrm{H}, J=6.9 \mathrm{~Hz}), 3.90(\mathrm{~d}, 3 \mathrm{H}$, $J=5.5 \mathrm{~Hz}), 3.87(\mathrm{~d}, 6 \mathrm{H}, J=5.3 \mathrm{~Hz}), 1.43-1.38(\mathrm{~m}, 27 \mathrm{H}) .{ }^{13} \mathrm{C}\left(100 \mathrm{MHz}, \mathrm{CDCl}_{3}\right): \delta 147.6,147.4,147.3$, 140.3, 139.1, 138.3, 136.3, 136.1, 136, 135.9, 134.8, 128.9, 127.4, 121.6, 116.4, 108.6, 108.3, 107.6, 105.9, 60.1, 59.9, 34.9, 31.6. FT-IR (KBr): 3421 (m), 3362 (m), 3044 (w), 2961 (s), 2902 (w), 2866 (w), $1586(\mathrm{~s})$, 1573 (s), 1519 (s), 1503 (s), 1475 (m), 1433 (s), 1381 (s), 1261 (m), 1209 (m), 1169 (w), 993 (m), 951 (w), $839(\mathrm{w}), 818(\mathrm{w}), 789(\mathrm{w}), 745(\mathrm{w}), 657(\mathrm{w}), 606(\mathrm{w}), 575(\mathrm{w}), 545(\mathrm{w}) \mathrm{cm}^{-1}$. HR-MS (EI): Calc'd for $\mathrm{C}_{51} \mathrm{H}_{58} \mathrm{O}_{3} \mathrm{~N}_{6}=802.4565$, found 802.4540 .

2-Oxy-1,3-bis[2-hydroxy-3-(8-quinolylamino)-5-(tert-butyl)phenylamino]-5-(tert-butyl)benzene (4) \& (oxidized 4). 3 (0.140 g, $0.174 \mathrm{mmol})$ was dissolved in $\mathrm{CH}_{2} \mathrm{Cl}_{2}(30 \mathrm{~mL})$ under an $\mathrm{N}_{2}$ atmosphere and cooled in ice-water with vigorous stirring. $\mathrm{BBr}_{3}$ solution $\left(1.57 \mathrm{mmol}, 1 \mathrm{M}\right.$ in $\mathrm{CH}_{2} \mathrm{Cl}_{2}$ ) was added drop-wise to the solution of 3 and the reaction was left to warm to room temperature over a $12 \mathrm{~h}$ period. Deoxygenated water $(15 \mathrm{~mL})$ was added to the reaction contents and the resulting mixture was rapidly stirred for another $0.5 \mathrm{~h}$ followed by dilution with $\mathrm{CH}_{2} \mathrm{Cl}_{2}(50 \mathrm{~mL})$ and water $(50 \mathrm{~mL})$. The aqueous layer was extracted with $3 \times 50 \mathrm{~mL} \mathrm{CH}_{2} \mathrm{Cl}_{2}$ and all of the organic extracts were combined and evaporated to an orange product that quickly turns brown. Yield, $0.112 \mathrm{~g}(85 \%)$. 4: MS (ESI+): $m / z 759\left(\mathrm{M}^{+}\right)$. Over a $48 \mathrm{~h}$ period the brown solid turns black (oxidized 4): HR-MS (EI+): Calc'd for $\mathrm{C}_{48} \mathrm{H}_{49} \mathrm{O}_{3} \mathrm{~N}_{6}=757.3861$, found = 757.3894. Anal. Calc'd for $\mathrm{C}_{48} \mathrm{H}_{49} \mathrm{O}_{3} \mathrm{~N}_{6}$ (found): $\mathrm{C}, 76.06$ (75.85); $\mathrm{H}$, 6.52 (6.68); N, 11.09 (11.24). FT-IR (KBr): 3356 (m), 3050 (w), 2959 (s), 2903 (w), $2866(\mathrm{w}), 1703$ (w), 1591 (s), $1573(\mathrm{~s}), 1514(\mathrm{~s}), 1473(\mathrm{~s}), 1456(\mathrm{~s}), 1421(\mathrm{~s}), 1379(\mathrm{~s}), 1361(\mathrm{~m}), 1329(\mathrm{~m}), 1256(\mathrm{~m}), 1215(\mathrm{~s}), 1198(\mathrm{~s})$, $1101(\mathrm{~m}), 1024(\mathrm{w}), 951(\mathrm{w}), 820(\mathrm{~m}), 789(\mathrm{~m}), 747(\mathrm{w}), 651(\mathrm{w}), 600(\mathrm{w}), 575(\mathrm{w}), 542 \mathrm{~cm}^{-1}(\mathrm{w})$. UV-Vis $\left(\mathrm{CH}_{2} \mathrm{Cl}_{2}\right): \lambda_{\max } \mathrm{nm}\left(\varepsilon\left(\mathrm{M}^{-1} \cdot \mathrm{cm}^{-1}\right)\right)=371\left(1.5 \times 10^{4}\right), 552\left(2.9 \times 10^{3}\right), 972\left(4.4 \times 10^{3}\right)$.

$\mathrm{Cu}_{4}\left(\mathrm{CH}_{3} \mathrm{CO}_{2}\right)_{2}\left(\mathrm{C}_{48} \mathrm{H}_{45} \mathrm{~N}_{6} \mathrm{O}_{3}{ }^{6-}\right)$ (5). 4 (0.150 g, $\left.0.200 \mathrm{mmol}\right)$ was dissolved in $\mathrm{MeOH}(40 \mathrm{~mL})$, excess triethylamine $(0.4 \mathrm{~mL})$ was added and the solution was left to stir for $5 \mathrm{~min}$. Solid $\mathrm{Cu}(\mathrm{OAc})_{2} \cdot 4 \mathrm{H}_{2} \mathrm{O}(0.220 \mathrm{~g}, 1.00 \mathrm{mmol})$ was added to the solution of 4 and the flask was stoppered and stirred for $48 \mathrm{~h}$ at room temperature. After this time, the reaction contents were left to slowly evaporate for approximately 3 weeks. A dark purple microcrystalline precipitate was collected by vacuum filtration, washed with water, and dried. Yield, $0.162 \mathrm{~g}(74 \%)$. Anal. Calc'd for $\mathrm{Cu}_{4} \mathrm{C}_{52} \mathrm{H}_{51} \mathrm{O}_{7} \mathrm{~N}_{6}$ (found): $\mathrm{C}, 55.46$ (55.89); $\mathrm{H}, 4.56$ (4.37); $\mathrm{N}, 7.46$ (7.21). MS (ESI+, $\left.\mathrm{CH}_{3} \mathrm{OH}\right): \mathrm{m} / z 1159\left[\mathrm{M}+\mathrm{CH}_{3} \mathrm{OH}+\right.$ $\left.\mathrm{H}^{+}\right]^{+}, 100 \%$. MS (MALDI+): $m / z 1150\left(\mathrm{MNa}^{+}\right)$. FT-IR (KBr): $3065(\mathrm{w}), 2961(\mathrm{~m}), 2868(\mathrm{w}), 1599(\mathrm{~m})$, $1575(\mathrm{~m}), 1539(\mathrm{~m}), 1499(\mathrm{~m}), 1464(\mathrm{~m}), 1420(\mathrm{~s}), 1327(\mathrm{~m}), 1273(\mathrm{~s}), 1252(\mathrm{~m}), 1240(\mathrm{~m}), 1196(\mathrm{~m}), 1175$ $(w), 1107(w), 1024(w), 989(w), 841(w), 820(w), 783(w), 733(w), 699(w), 638(w), 543(w), 436 \mathrm{~cm}^{-1}$ (w). UV-Vis $(\mathrm{MeOH}): \lambda_{\max }=645 \mathrm{~nm}$.

\section{Conclusions}

In summary we have reported the synthesis and coordination chemistry of a novel polytopic paramagnetic ligand. When coordinated with $\mathrm{Cu}^{2+}$ this ligand adopts a hexa-anion radical oxidation state with very strong intramolecular antiferromagnetic exchange coupling. We are developing the coordination chemistry further and anticipate similar exchange coupling constants but larger overall ground state spin values through ferromagnetic or ferromagnetic interaction transition metal ions other than $\mathrm{Cu}^{2+}$. In our opinion, these redox-active ligands hold strong promise for new molecule-based materials as well as for other aspects of RAL chemistry. The synthetic method can be expanded to other derivatives, which we will report on in due course.

Supplementary Materials: The following are available online at www.mdpi.com/2312-7481/3/1/15/s1, various spectroscopic data, X-ray, and electrochemical data.

Acknowledgments: NSERC, CFI, and Brock University are thanked for funding and Art van der Est (Brock University) for the use of his EPR facility.

Author Contributions: M.T.L. conceived and designed the experiments and wrote the manuscript. A.J.L. carried out single crystal X-ray diffraction experiments and solved the structure presented herein. N.M.B. performed all synthetic experiments and P.K.P. carried out EPR spectroscopy experiments. 
Conflicts of Interest: The authors declare no conflict of interest.

\section{References}

1. Luca, O.R.; Crabtree, R.H. Redox-active ligands in catalysis. Chem. Soc. Rev. 2013, 42, 1440-1459. [CrossRef] [PubMed]

2. Lyaskovskyy, V.; De Bruin, B. Redox non-innocent ligands: Versatile new tools to control catalytic reactions. ACS Catal. 2012, 2, 270-279. [CrossRef]

3. Praneeth, V.K.K.; Ringenberg, M.R.; Ward, T.R. Redox-active ligands in catalysis. Angew. Chem. Int. Ed. 2012, 51, 10228-10234. [CrossRef] [PubMed]

4. Kaim, W.; Schwederski, B. Non-innocent ligands in bioinorganic chemistry-An overview. Coord. Chem. Rev. 2010, 254, 1580-1588. [CrossRef]

5. Lyons, C.T.; Stack, T.D.P. Recent advances in phenoxyl radical complexes of salen-type ligands as mixed-valent galactose oxidase models. Coord. Chem. Rev. 2013, 257, 528-540. [CrossRef] [PubMed]

6. Paul, N.D.; Rana, U.; Goswami, S.; Mondal, T.K.; Goswami, S. Azo anion radical complex of rhodium as a molecular memory switching device: isolation, characterization, and evaluation of current-voltage characteristics. J. Am. Chem. Soc. 2012, 134, 6520-6523. [CrossRef] [PubMed]

7. D'Alessandro, D.M. Exploiting redox activity in metal-organic frameworks: Concepts, trends and perspectives. Chem. Commun. 2016, 52, 8957-8971. [CrossRef] [PubMed]

8. Tezgerevska, T.; Alley, K.G.; Boskovic, C. Valence tautomerism in metal complexes: Stimulated and reversible intramolecular electron transfer between metal centers and organic ligands. Coord. Chem. Rev. 2014, 268, 23-40. [CrossRef]

9. DeGayner, J.A.; Jeon, I.-R.; Harris, T.D. A series of tetraazalene radical-bridged $M_{2}\left(M=\mathrm{Cr}{ }^{\mathrm{III}}, \mathrm{Mn}^{\mathrm{II}}, \mathrm{Fe}^{\mathrm{II}}\right.$, Co II ) complexes with strong magnetic exchange coupling. Chem. Sci. 2015, 6639-6648. [CrossRef]

10. Jeon, I.-R.; Park, J.G.; Xiao, D.J.; Harris, T.D. An Azophenine Radical-Bridged Fe2 Single-Molecule Magnet with Record Magnetic Exchange Coupling. J. Am. Chem. Soc. 2013, 135, 16845-16848. [CrossRef] [PubMed]

11. Demir, S.; Jeon, I.; Long, J.R.; Harris, T.D. Radical ligand-containing single-molecule magnets. Coord. Chem. Rev. 2015, 289-290, 149-176. [CrossRef]

12. Bonanno, N.M.; Lough, A.J.; Prosser, K.E.; Walsby, C.J.; Poddutoori, P.K.; Lemaire, M.T. A stable open-shell redox active ditopic ligand. Dalton Trans. 2016, 3, 5460-5463. [CrossRef] [PubMed]

13. Surry, D.S.; Buchwald, S.L. Dialkylbiaryl phosphines in Pd-catalyzed amination: A user's guide. Chem. Sci. 2011, 2, 27-50. [CrossRef] [PubMed]

14. Broere, D.L.J.; Plessius, R.; van der Vlugt, J.I. New avenues for ligand-mediated processes—Expanding metal reactivity by the use of redox-active catechol, $o$-aminophenol and $o$-phenylenediamine ligands. Chem. Soc. Rev. 2015, 44, 6886-6915. [CrossRef] [PubMed]

15. Min, K.S.; Weyhermüller, T.; Wieghardt, K. O,N-Coordinated $o$-iminobenzoquinone and o-iminobenzosemiquinonato(1-) ligands in complexes of $\mathrm{Ni}(\mathrm{II}), \mathrm{Co}(\mathrm{III})$ and $\mathrm{Fe}(\mathrm{III})$. Dalton Trans. 2003, 1126-1132.

16. Min, K.S.; Weyhermüller, T.; Wieghardt, K. Coordination chemistry of 2-(8-aminoquinolino)-4,6-di-tertbutylphenol with manganese(IV), iron(III), and cobalt(II/III):N,O-coordinated $o$-iminobenzosemiquinonate(1-) pi radical monoanions vs.o-iminophenolate(2-) dianions. Dalton Trans. 2004, 178-186.

17. Chilton, N.F.; Anderson, R.P.; Turner, L.D.; Soncini, A.; Murray, K.S. PHI: a powerful new program for the analysis of anisotropic monomeric and exchange-coupled polynuclear d- and f-block complexes. J. Comput. Chem. 2013, 34, 1164-1175. [CrossRef] [PubMed]

18. Ahlrichs, R.; Bär, M.; Häser, M.; Horn, H.; Kölmel, C. Electronic structure calculations on workstation computers: The program system turbomole. Chem. Phys. Lett. 1989, 162, 165-169. [CrossRef]

19. Treutler, O.; Ahlrichs, R. Efficient molecular numerical integration schemes. J. Chem. Phys. 1995, 102, $346-354$. [CrossRef]

20. Ahlrichs, R.; Bäcker, S.; Ehrig, M.; Eichkorn, K.; Elliott, S.; Haase, F.; Häser, M.; Horn, H.; Huber, C.; Huniar, U.; et al. TURBOMOLE V6.5 2013, a Development of University of Karlsruhe, and Forschungszentrum Karlsruhe GmbH, 1987-2007, TURBMOLE GmbH, since 2007. Available online: http:/ / www.turbomole.com (accessed on 13 March 2017). 
21. Schafer, A.; Horn, H.; Ahlrichs, R. Fully Optimized Contracted Gaussian-Basis Sets for Atoms Li to Kr. J. Chem. Phys. 1992, 97, 2571-2577. [CrossRef]

22. Weigend, F.; Ahlrichs, R. Balanced basis sets of split valence, triple zeta valence and quadruple zeta valence quality for $\mathrm{H}$ to Rn: Design and assessment of accuracy. Phys. Chem. Chem. Phys. 2005, 7, 3297-3305. [CrossRef] [PubMed]

23. Becke, A.D. Density-functional exchange-energy approximation with correct asymptotic behavior. Phys. Rev. A 1988, 38, 3098-3100. [CrossRef]

24. Vosko, S.H.; Wilk, L.; Nusair, M. Accurate spin-dependent electron liquid correlation energies for local spin density calculations: a critical analysis. Can. J. Phys. 1980, 58, 1200-1211. [CrossRef]

25. Perdew, J.P. Density-functional approximation for the correlation energy of the inhomogeneous electron gas. Phys. Rev. B 1986, 33, 8822-8824. [CrossRef]

26. Eichkorn, K.; Htiser, M.; Ahlrichs, R.; Eichkorn, K.; Treutler, O.; Marco, H.; Ahlrichs, R. Auxiliary basis sets to approximate Coulomb potentials. Chem. Phys. Lett. 1995, 240, 283-290. [CrossRef]

27. Eichkorn, K.; Weigend, F.; Treutler, O.; Ahlrichs, R. Auxiliary basis sets for main row atoms and transition metals and their use to approximate Coulomb potentials. Theor. Chem. Acc. 1997, 97, 119-124. [CrossRef]

28. Sierka, M.; Hogekamp, A.; Ahlrichs, R. Fast evaluation of the Coulomb potential for electron densities using multipole accelerated resolution of identity approximation. J. Chem. Phys. 2003, 118, 9136-9148. [CrossRef]

29. Bauernschmitt, R.; Häser, M.; Treutler, O.; Ahlrichs, R. Calculation of excitation energies within time-dependent density functional theory using auxiliary basis set expansions. Chem. Phys. Lett. 1997, 264, 573-578. [CrossRef]

30. Deglmann, P.; May, K.; Furche, F.; Ahlrichs, R. Nuclear second analytical derivative calculations using auxiliary basis set expansions. Chem. Phys. Lett. 2004, 384, 103-107. [CrossRef]

31. Becke, A.D. Density-functional thermochemistry. III. The role of exact exchange. J. Chem. Phys. 1993, 98, 5648-5652. [CrossRef]

32. Lee, C.; Yang, W.; Parr, R.G. Development of the Colle-Salvetti correlation-energy formula into a functional of the electron density. Phys. Rev. B 1988, 37, 785-789. [CrossRef]

33. Frisch, M.J.; Trucks, G.W.; Schlegel, H.B.; Scuseria, G.E.; Robb, M.A.; Cheeseman, J.R.; Scalmani, G.; Barone, V.; Mennucci, B.; Petersson, G.A.; et al. Gaussian 09, Revision D. 01; Gaussian, Inc.: Wallingford, CT, USA, 2009.

34. Skripnikov, L.V.; Chemissian, V. 4.01, Visualization Computer Program. 2014. Available online: www. chemissian.com (accessed on 13 March 2017).

(C) 2017 by the authors. Licensee MDPI, Basel, Switzerland. This article is an open access article distributed under the terms and conditions of the Creative Commons Attribution (CC BY) license (http:/ / creativecommons.org/licenses/by/4.0/). 